\title{
Risk effects of low temperature and high humidity on the spread of COVID-19 in California: Time series study
}

\section{Lanlan Fang}

Anhui Medical University

Dingjian Wang

Anhui Medical University

Guixia Pan ( $D$ pgxkd@163.com )

Anhui Medical University https://orcid.org/0000-0002-1278-8486

\section{Research Article}

Keywords: COVID-19, temperature, humidity, DLNM, California

Posted Date: December 15th, 2020

DOI: https://doi.org/10.21203/rs.3.rs-126531/v1

License: (c) (i) This work is licensed under a Creative Commons Attribution 4.0 International License.

Read Full License 

COVID-19 in California: Time series study

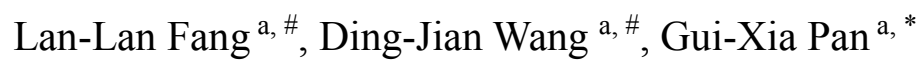

${ }^{\text {a }}$ Department of Epidemiology and Biostatistics, School of Public Health, Anhui considered co-first authors. fanglanlanxi@163.com; Wangdingjian666@163.com.

$9 \quad$ Email: pgxkd@163.com. 
Background: Previous researches inferred that 'summer' might weaken COVID-19 transmission. However, with the warming weather coming, the COVID-19 pandemic was still intensifying.

Methods: This study aimed to investigate the associations between temperature, relative humidity, and COVID-19 cases using the Distributed Lag Non-linear Model (DLNM) from Jan $27^{\text {th }}$ to July $15^{\text {th }}, 2020$, in California, US.

Results: It showed that as of July 15, 2020, there were 355285 reported cases in California, where the temperature was between $6.33^{\circ} \mathrm{C}$ and $30.72^{\circ} \mathrm{C}$ and the relative humidity was between $23 \%$ and $100 \%$. Temperature from $6.33{ }^{\circ} \mathrm{C}$ to $9{ }^{\circ} \mathrm{C}$, relative humidity from $80 \%$ to $98 \%$ were the risky factors of COVID-19 transmission. It increased the risk of $95.4 \%$ at $6.33{ }^{\circ} \mathrm{C}$ (RR:1.954; CI: 1.032-3.701). It increased the risk of $70.3 \%$ when the humidity was $98 \%$ (RR: 1.703 , CI: $1.049-2.765)$. When the temperature $>9{ }^{\circ} \mathrm{C}$ and the relative humidity $<80 \%$, there was no statistical association.

Conclusions: This suggested that in winter with low temperature and high humidity, the spread of the COVID-19 would be severe due to weather factors. However, temperature and humidity were not related to the COVID-19 pandemic in summer. It did not mean that 'summer' would weaken the spread of COVID-19 in California. Therefore, special attention should be paid to the prevention and treatment of COVID19 in the winter. And it cannot be ignored in summer, otherwise, it will also cause a counterattack against the epidemic.

Keywords: COVID-19, temperature, humidity, DLNM, California. 


\section{Introduction}

COVID-19 is caused by the severe acute respiratory syndrome coronavirus 2 (SARS-CoV-2), a novel coronavirus. The World Health Organization (WHO) categorized COVID-19 as a pandemic on March 11, 2020 (https://www.who.int/ $\mathrm{dg} /$ speeches/detail/who-director-general-s-opening-remarks-at-the-media-briefing-oncovid-19---11-march-2020). Due to the high contiguousness and widespread, the COVID-19 pandemic has been the most serious global crisis, affecting almost all countries on our planet since World War-II [1]. Globally, as of July $9^{\text {th }}, 202$ 0 , there have been 11,874,226 confirmed cases of COVID-19, including 545,481 d eaths, reported to WHO (https://www.who.int/dg/speeches/detail/who-director-gene $\underline{\text { ral-opening-remarks-at-the-member-state-briefing-on-the-covid-19-pandemic-evaluati }}$ on---9-july-2020). The pandemic is still growing in most countries and is far fr om under control.

Many studies suggested that environmental factors were risk factors for acute infectious diseases. For instance, a study based on Hong Kong, Guangzhou, Beijing, and Taiyuan indicated that the outbreaks of SARS were significantly related to temperature [2]. Another study in US cities indicated that humidity was the best predictor of COVID-19 transmission [3].

The relationship between environmental factors and COVID-19 has been a hot topic of great concern by scholars all over the world since the emergence of COVID19. Temperature and humidity played a significant role in the seasonal spread of coronaviruses [4]. A laboratory review suggested that SARS-CoV-2 can survive longer 
in environments with lower temperature and lower relative humidity [5]. Another laboratory study also reported that the viability of coronaviruses reduced rapidly when the temperature or relative humidity increased [6]. Most epidemiological studies [3,79] also suggested that the weather with low temperature and low humidity likely favored the transmission of COVID-19. However, a Brazilian study [10] showed that higher mean temperature and average relative humidity favored the COVID-19 transmission, differently from reports from coldest countries or periods under cool temperatures.

People generally believe the hypothesis that coronaviruses are not easily transmitted in hot and humid conditions [11]. In 2005, Lin et al. found that the risk of increased daily incidence of SARS in lower temperatures was 18.18 -fold (95\% CI: 5.68.8) higher than that in higher temperatures in Hong Kong [12]. Like the SARS, its epidemic was gradually faded with the warming weather coming and was ended in July $2003[2,13,14]$.

Liu et al. indicated that the COVID-19 might gradually ease as a result of rising temperatures in the coming months [8]. However, another study having the same research background showed that mean temperature and COVID-19 confirmed cases was an approximately positive linear relationship in the range of $<3{ }^{\circ} \mathrm{C}$ and became flat above $3{ }^{\circ} \mathrm{C}$ and COVID-19 may not perish of itself without any public health interventions when the weather becomes warmer [15]. Bashir et al. also reported similar findings for COVID-19 cases in New York, US [16]. Auler et al. concluded that high temperature and humidity did not reduce the transmission of COVID-19 in tropical 
regions [10]. Therefore, there is currently no consensus on the impact of temperature and humidity on the transmission of COVID-19.

The temperature is gradually warming, but the global epidemic is still intensifying, breaking through 10 million, and there is no downward trend. Due to the severe situation and the heterogeneity of different regional backgrounds, the relationship between temperature, humidity, and COVID-19 deserves further discussion.

California is located on the west coast of the United States, with an area of about 410,000 square kilometers, a population of about 37.69 million, and a population density of about 86 people per square kilometer. California has been one of the hardesthit states since the outbreak of COVID-19 in the United States. As of July $26^{\text {th }}$, California ranked first in the United States with more than 440,000 cases.

In this study, we explored the effects of temperature and humidity on COVID-19 transmission in California, US. We studied the relationship between daily temperature, daily relative humidity, and new confirmed COVID-19 cases using the Distributed Lag Non-linear Model (DLNM), and also investigated the delayed effects of specific temperature and humidity during the period Jan $27^{\text {th }}-$ July $15^{\text {th }}, 2020$.

\section{Materials and methods}

\section{COVID-19 data}

As of July $15^{\text {th }}, 2020$, data on daily new confirmed COVID-19 cases wer e collected from the Johns Hopkins Center for Systems Science and Engineerin g repository (https://github.com/CSSEGISandData/COVID-19). Since uncertain an 
$d$ anonymous data on the incidence of cases were obtained from a publicly ac cessible data website, this study did not involve the consent of the participants, and there was no need for institutional review.

\section{Meteorological data}

The monitoring station, SACRAMENTO MCCLELLAN AFB, CA, US was used. Sacramento, the capital of California, is located between $38^{\circ} 34^{\prime} \mathrm{N}$ and $121^{\circ} 28^{\prime} \mathrm{E}$. Daily meteorological data, including daily average temperature, average dew point, and average wind speed, were obtained from the National Oceanic and Atmospheric Administration Center (https://www.ncei.noaa.gov/access/search/data-search/globalsummary-of-the-day).

\section{Calculation of relative humidity}

The relative humidity is the ratio of the actual water vapor pressure to the saturated water vapor pressure, calculated using the following formula:

$$
R H=\frac{E}{E_{W}} \times 100 \%
$$

$R H$ represents the relative humidity. $E$ contributes to the air vapor pressure. $E_{W}$ gives the saturated vapor pressure. The dew point is the temperature at which the air must be cooled to become saturated with water vapor. The dew point temperature can be used to calculate the actual vapor pressure $E$, and the actual temperature can be used to calculate the saturated vapor pressure $E_{W}[17]$, calculated using the following formula:

$$
E=E_{0} \times e^{\frac{A t}{B+t}}
$$

where $E_{0}$ represents the saturated vapor pressure at the reference temperature $\mathrm{T}_{0}$ $(273.15 \mathrm{~K}$ ) which equals $6.11 \mathrm{Mb} . A$ is a constant of 17.43 and $B$ is a constant of 240.73 . 
$t\left({ }^{\circ} \mathrm{C}\right)$ is the actual temperature or dew point.

\section{Statistical analysis}

We conducted the time-series regression analysis to find associations between daily temperature, relative humidity, and daily new confirmed cases of COVID-19. As the response variable was composed of daily new counts, we used the quasi-Poisson regression model, which can capture over dispersion often present in count data [18].

We used the DLNM to capture non-linear relationships and lagged associations with the application of the "cross-basis" function (a two-dimensional basis function) [19].

$$
\text { The model is as follows[20]: }
$$

$$
\mathrm{y}_{t} \sim \text { quasi-Poisson }\left(\mu_{t}\right)
$$

$$
\begin{aligned}
& \log \left(\mu_{t}\right)=\alpha+\beta_{1} \text { cb.Temp }+n s(R H, 3)+n s(\text { WS , 3 })+n s(\text { time , 3 }) \\
& \log \left(\mu_{t}\right)=\alpha+\beta_{2} c b . R H+n s(\text { Temp , 3) }+n s(\text { WS , 3 })+n s(\text { time, 3) }
\end{aligned}
$$

In the model, $\mu_{t}$ was the counts of daily new confirmed cases of COVID-19 for day $t$ (added one to avoid taking the logarithm of zeros [21]. $\alpha$ was the intercept. Temp represented daily average temperature. $\beta_{1}, \beta_{2}$ were the vector of regression coefficients for $c b$.Temp, $c b . R H$, which were the cross-basis matrix of temperature, relative humidity. The maximum lag day was set as 7 days, which was based on previous studies [3]. We allowed for non-linear relationships by using a natural cubic spline with 3 degrees of freedom (df), and the lagged effects were modeled using a natural cubic spline with an intercept and three internal knots placed at equally-spaced $\log$-values. ns () is the natural cubic spline. WS represented average wind speed, $3 \mathrm{df}$ was used to adjust for average wind speed. Besides, time was used as a variable to 
control the long-term trend effect using 3 df [22].

According to the three-dimension plot between temperature (Fig. 2a), relative humidity (Fig. 3a), and COVID-19 cases, determine a temperature of $20^{\circ} \mathrm{C}$ and relative humidity of $60 \%$ as reference values. Set the 5th (defined as low), 25th (defined as lower), 75th (defined as higher), and 95th percentile (defined as high) of daily temperature and relative humidity as different groups to study delayed effects of specific temperature and humidity on daily new confirmed COVID-19 cases[23].

All the statistical analyses were performed in R 3.6.2 software with the 'dlnm' and 'splines' packages. The two-sided P-value $<0.05$ was considered statistically significant.

\section{Sensitivity analysis}

To evaluate the robustness of the model, a sensitivity analysis was performed using the assessment of several $\mathrm{dfs}$ : temperature $(\mathrm{df}=2,4)$, relative humidity $(\mathrm{df}=2,4)$, wind speed $(\mathrm{df}=2,4)$, time $(\mathrm{df}=2,4)$. The maximum lag day of temperature, relative humidity was also set to 6,8 to examine the sensitivity of the effects.

\section{Results}

\section{Characteristics of COVID-19 and meteorological variables}

The characteristics of COVID-19 and meteorological variables were shown in Table 1. During the study period from Jan $27^{\text {th }}$ to July $15^{\text {th }}, 2020$ (171 days), a total of 355285 confirmed cases were included in California, US. The number of daily new cases during this period ranged from 0 to 12978 (mean \pm SD, $2076 \pm 2604$, median 1372). The temperature gradually increased during the observation period. The 
temperature levels ranged from $6.33{ }^{\circ} \mathrm{C}$ to $30.72{ }^{\circ} \mathrm{C}$ (mean $\pm \mathrm{SD}, 17.53 \pm 6.13$, median 16.39). The relative humidity gradually decreased during the observation period. The relative humidity levels ranged from $23 \%$ to $100 \%$ (mean $\pm \mathrm{SD}, 55 \% \pm 0.19$, median 53\%). Fig. 1 (a), (b), (c) showed trends for daily new confirmed cases, temperature, and relative humidity respectively.

Table1. Characteristics of COVID-19 and meteorological variables 2020.1.272020.7.15.

\begin{tabular}{|c|c|c|c|c|c|c|c|c|c|}
\hline \multirow[t]{2}{*}{ Group } & \multirow[t]{2}{*}{ Mean } & \multirow[t]{2}{*}{$\mathrm{SD}$} & \multirow[t]{2}{*}{ Min } & \multirow[t]{2}{*}{$\operatorname{Max}$} & \multirow[t]{2}{*}{ Median } & \multicolumn{4}{|c|}{ Frequency distribution } \\
\hline & & & & & & P5 & $\mathrm{P} 25$ & P75 & P95 \\
\hline Cases & 2076 & 2604 & 1 & 12978 & 1372 & 1 & 17 & 2783 & 8256 \\
\hline Temp & 17.53 & 6.13 & 6.33 & 30.72 & 16.39 & 9.42 & 12.06 & 22.34 & 27.951 \\
\hline RH & $55 \%$ & 0.19 & $23 \%$ & $100 \%$ & $53 \%$ & $29 \%$ & $39.5 \%$ & $69 \%$ & $89 \%$ \\
\hline WDSP & 6.28 & 2.80 & 0.80 & 15.70 & 6.00 & 2.16 & 4.30 & 8.20 & 11.18 \\
\hline
\end{tabular}

Cases, daily new cases of COVID-19; SD, standard deviation; Min, minimum; Max, maximum. P5, P25, P75, P95: the 5th percentile, the 25th percentile, the 75th percentile, the 95th percentile.

\section{Overall effects of temperature and humidity on COVID-19 transmission}

The relationship between temperature and new daily confirmed COVID-19 cases was presented in Fig. 2a. At $\operatorname{lag} 0$, there was a non-linear relationship between temperature and the relative risk (RR) of COVID-19, with a temperature of $20^{\circ} \mathrm{C}$ corresponding to the minimum COVID-19 risk. As the number of lag days increased, the effect was gradually diminishing. The overall cumulative relative risk was presented in Fig. 2b. We found that as the temperature rose, the effect gradually weakened. The 
RR at $6.33-9{ }^{\circ} \mathrm{C}(\mathrm{RR}: 1.475-1.954$; CI: $1.008-3.701)$ was statistically significant and

202 was the maximum at $6.33^{\circ} \mathrm{C}$ (RR: 1.954 ; CI: $\left.1.032-3.701\right)$.

203 The relationship between relative humidity and new daily confirmed cases was

204 presented in Fig. 3a. There was an obvious lag effect under high humidity conditions.

205 At $\mathrm{RH}=98 \%, \mathrm{Lag}=4$, the RR of relative humidity was the highest (RR: 1.094, CI:

206 1.015-1.177) compared to the reference of $60 \%$. The overall cumulative relative risk

207 was presented in Fig. 3b. We found that as the relative humidity rose, the effect

208 gradually strengthened. The RR for relative humidity was statistically significant from

$20980 \%$ to $98 \%$ (RR: $1.196-1.703$, CI: $1.019-2.765$ ) with the reference of $60 \%$, and was

210 the maximum at $98 \%$ (RR: $1.703, \mathrm{CI}: 1.049-2.765)$.

211 Delayed effects of specific temperature and humidity on COVID-19 transmission

212 Delayed effects between the RRs of COVID-19 and temperature in different 213 groups $\left(\mathrm{P} 5,9.42{ }^{\circ} \mathrm{C} ; \mathrm{P} 25,12.06{ }^{\circ} \mathrm{C}\right.$; P75, $22.34{ }^{\circ} \mathrm{C}$; P95, $\left.27.95{ }^{\circ} \mathrm{C}\right)$ were presented in 214 Fig. 4 and Table 2 respectively. With the reference of $20^{\circ} \mathrm{C}$, the single-day lagged 215 effects of specific temperature on daily new confirmed cases were shown in Fig. 4. The 216 single-day lagged effects of specific temperature on COVID-19 cases were not 217 statistically significant. The cumulative lag effects of specific temperature on daily new 218 confirmed cases were shown in Table 2 . At the low temperature (P5: $\left.9.42^{\circ} \mathrm{C}\right)$ group, 219 the cumulative lag effect increased the risk of COVID from lag $0-4$ days $(\mathrm{RR}=1.463$, 220 95\%CI: 1.054-2.030) and lasted until lag 0-7 days ( $R R=1.423,5 \% C I: 1.000-2.026)$. 221 The greatest cumulative lag effect emerged on lag 0-4 days and increased $46.3 \%$ of the 222 risk of on daily new confirmed cases $(\mathrm{RR}=1.463,95 \% \mathrm{CI}$ : $1.054-2.030)$. 
Table2. Cumulative lag effects of specific temperatures on COVID-19 at various lag days.

\begin{tabular}{|c|c|c|c|c|c|c|c|}
\hline lag P5 & $95 \% \mathrm{CI}$ & $\mathrm{P} 25$ & $95 \% \mathrm{CI}$ & P75 & $95 \% \mathrm{CI}$ & P95 & $95 \% \mathrm{CI}$ \\
\hline $0-41.463$ & $(1.054-2.030$ & ) $* 1.203$ & $(0.946-1.530)$ & 1.008 & $(0.956-1.066)$ & 1.050 & $(0.863-1.278)$ \\
\hline $0-51.458$ & (1.041- 2.044 & ) $* 1.178$ & $(0.926-1.500)$ & 1.016 & $(0.961-1.074)$ & 1.056 & $(0.856-1.301)$ \\
\hline $0-61.462$ & (1.029- 2.077 & ) $* 1.173$ & $(0.917-1.502)$ & 1.018 & $(0.960-1.079)$ & 1.059 & $(0.847-1.322)$ \\
\hline $0-71.423$ & $(1.000-2.026$ & 6) $* 1.165$ & $(0.906-1.499)$ & 1.016 & $(0.956-1.080)$ & 1.060 & $(0.842-1.335)$ \\
\hline
\end{tabular}

P5; P25; P75; P95: the 5th percentile $\left(9.42{ }^{\circ} \mathrm{C}\right)$; the 25 th percentile $\left(12.06{ }^{\circ} \mathrm{C}\right)$; the 75 th perc

$* \mathrm{P}<0.05$.

Delayed effects between the RRs of COVID-19 and humidity in different groups

3 respectively. With the reference of $60 \%$, the single-day lagged effects of specific humidity on daily new confirmed cases were shown in Fig. 5. At the high humidity (P95: 89.0\%) group, the single-day lagged effects had statistical significance from lag3 to lag5. The $\mathrm{RR}$ value reached the highest at lag $4(\mathrm{RR}=1.093,95 \% \mathrm{CI}: 1.016-1.177)$, which indicated that the risk of lag effect increased by $9.3 \%$. However, the single-day lagged effects in the other groups were not statistically significant. At the high humidity (P95: 89.0\%) group, the cumulative lag effect increased the risk from lag 0-4 days (RR $=1.376,95 \% \mathrm{CI}: 1.031-1.837)$ and lasted until lag 0-7 days $(\mathrm{RR}=1.410,95 \% \mathrm{CI}: 1.040-$ of the risk of on daily new confirmed cases $(\mathrm{RR}=1.423,95 \% \mathrm{CI}$ : $1.070-1.892)$. 
Table3. Cumulative lag effects of specific humidity on COVID-19 at various lag days.

\begin{tabular}{lcccccccc}
\hline lag & $\mathrm{P} 5$ & $95 \% \mathrm{CI}$ & $\mathrm{P} 25$ & $95 \% \mathrm{CI}$ & $\mathrm{P} 75$ & $95 \% \mathrm{CI}$ & $\mathrm{P} 95$ & $95 \% \mathrm{CI}$ \\
\hline $0-4$ & $1.029(0.844-1.254)$ & $1.040(0.849-1.273)$ & $1.043(0.969-1.123)$ & $1.376(1.031-1.837) *$ \\
\hline $0-5$ & $1.064(0.866-1.307)$ & $1.065(0.869-1.305)$ & $1.039(0.965-1.118)$ & $1.383(1.047-1.825) *$ \\
$0-6$ & $1.092(0.874-1.365)$ & $1.082(0.873-1.342)$ & $1.040(0.962-1.126)$ & $1.423(1.070-1.892) *$ \\
$0-7$ & $1.110(0.869-1.417)$ & $1.085(0.864-1.363)$ & $1.040(0.956-1.132)$ & $1.410(1.040-1.911) *$ \\
\hline
\end{tabular}

P5; P25; P75; P95: the 5th percentile(29.0\%); the 25th percentile $(39.5 \%)$; the 75th percentil

e $(69.0 \%)$; the 95 th percentile $(89.0 \%)$.

$* \mathrm{P}<0.05$

\section{Sensitivity analysis}

The result of sensitivity analysis indicated that the model was robust when the dfs

were altered for temperature $(\mathrm{df}=2,4)$, humidity $(\mathrm{df}=2,4)$, wind speed $(\mathrm{df}=2,4)$, time

$(\mathrm{df}=2,4)$ (Fig. S1, Fig. S2). Changing the maximum lag day into 6,8 in the model didn't show significant differences for the fitting effect of the model either (Fig. S3, Fig. S4). The exposure-response curve was similar before and after adjusting.

\section{Discussion}

The COVID-19 pandemic is a global health crisis and the greatest challenge facing the world [17]. In this study, we examined whether temperature and humidity were associated with the transmission of COVID-19 in California, US. We found that low temperature and high humidity were the risky factors of COVID-19 transmission. However, when the temperature $>9{ }^{\circ} \mathrm{C}$ and the relative humidity $<80 \%$, there was no 
statistical association.

In our study, the RR at $6.33-9{ }^{\circ} \mathrm{C}$ had statistically significant between COVID-19 and temperature, and increased risk of illness. Furthermore, at the low temperature $\left(9.42{ }^{\circ} \mathrm{C}\right)$ group, the greatest cumulative lag effect emerged on lag $0-4$ days and increased $46.3 \%$ of the risk. These suggested that temperature was a risk factor under low-temperature conditions. Many previous studies supported this finding. Chin et al. reported that SARS-CoV-2 was highly stable at $4{ }^{\circ} \mathrm{C}$ but sensitive to heat. The virus survival time was shortened to $5 \mathrm{~min}$ as the incubation temperature increased to $70{ }^{\circ} \mathrm{C}$ [24]. Ujiie et al. suggested that there was an association between low temperature and increased risk of COVID-19 infection [9]. Xie and Zhu also indicated that under the condition that the temperature is less than $3{ }^{\circ} \mathrm{C}$, each $1{ }^{\circ} \mathrm{C}$ rose was associated with a 4.861\% (95\% CI: 3.209-6.513) increased in the daily number of COVID-19 confirmed cases [15].

In our study, when the temperature was higher than $9^{\circ} \mathrm{C}$, we found that there is no statistical relationship. It indicated that the COVID-19 pandemic could not be suppressed with temperature increases. A case-crossover design with DLNM in Albany GA US, which median daily temperature was $18.78^{\circ} \mathrm{C}$, shown that temperature was not a significant predictor of COVID-19 cases [3]. Another study from Brazil showed that the COVID-19 transmission rate was favored by higher mean temperatures $\left(27.5^{\circ} \mathrm{C}\right)[10]$. These studies supported this finding.

We found that when the relative humidity is between $80 \%$ and $98 \%$, the humidity was the risky factors of COVID-19 transmission. There was no correlation under lower 
humidity conditions. Similar conclusions from research on multiple cities in the United States. In the high-humidity cities of Albany and New Orleans (median the relative humidity: $9.88 \mathrm{~g} / \mathrm{kg}, 12.99 \mathrm{~g} / \mathrm{kg}$ ), there was a significant relationship. Humidity resulted in an up to two-fold increased risk of transmission. In New York City, where the humidity is lower (median the relative humidity: $3.98 \mathrm{~g} / \mathrm{kg}$ ), no relationship was observed between humidity and COVID-19 cases [3]. Auler et al. also found that higher average relative humidity (>77.7\% ) might favor the evolution of COVID-19 in Brazil [10]. However, some studies have reported conflicting results. Wu et al. reported that for every $1 \%$ increase in humidity, daily new cases of COVID-19 reduced by $0.85 \%$ [17]. It might be because the research background was in cold and dry winter and the humidity range was limited.

Our results suggested that temperature and humidity in summer were not related to the COVID-19 pandemic. However, there was a sharp increase in July in California. The reasons are as follows: First, the White House wanted to press forward on the resumption of work and production, including for schools. Blindly opening up too quickly is an important reason for the worsening of the epidemic. Second, the American public generally relaxed precautionary awareness. People did not wear masks and were unwilling to observe social distancing. Third, the detected infected could not be effectively isolated. Most people were consciously isolated at home, which could easily cause family cluster infections.

The advantages of this study are as follows. First, this study was a time series analysis using DLNM, which not only allowed the model to maintain a detailed time 
course of the non-linear exposure-response relationship, but it also generated an estimate for the overall effect of an exposure on a health outcome over different lagged or delayed periods [19]. Second, we eliminated the long-term trend of the COVID-19 epidemic, and daily meteorological data were used to accurately reflect the effect of temperature and humidity on the transmission of COVID-19.

However, several limitations must be considered. First, confounding factors such as other environmental parameters and intervention measures were not controlled in the model. Second, the impact of temperature and humidity on sex and age could not be analyzed because the key information was not available on the official website. Third, Meteorological data from Sacramento, the capital of California, was used to represent entire California.

\section{Conclusions}

This suggested that in winter with low temperature and high humidity, the spread of the COVID-19 would be severe due to weather factors. However, temperature and humidity were not related to the COVID-19 pandemic in summer. It did not mean that 'summer' would weaken the spread of COVID-19 in California. Therefore, special attention should be paid to the prevention and treatment of COVID-19 in the winter. And it cannot be ignored in summer, otherwise, it will also cause a counterattack against the epidemic.

\section{Declarations}

Ethical approval and consent to participate 
Not applicable.

\section{Consent for publication}

Not applicable.

\section{Availability of data and material}

The datasets used and/or analyzed during the current study are available from the websites.

\section{Competing interests}

The authors declare that they have no known competing financial interests or personal relationships that could have appeared to influence the work reported in this paper.

\section{Funding}

This paper was supported by the Special Funding for the Prevention and Control of New Coronary Pneumonia Epidemic from China Postdoctoral Science Foundation (2020T130001ZX), the Anhui Medical University Doctoral Research Foundation (XJ201414), the Anhui Postdoctoral Foundation (2017B237).

\section{Authors' Contribution} Fang.; software, Dingjian Wang.; validation, Dingjian Wang.; formal analysis, Lanlan

Guixia Pan.; visualization, Lanlan Fang.; supervision, Guixia Pan.; project administration, Guixia Pan.; funding acquisition, Guixia Pan. All authors have read and agreed to the published version of the manuscript. 


\section{Acknowledgements}

Not applicable.

\section{References}

1. Boccaletti, S.; Ditto, W.; Mindlin, G.; Atangana, A. Modeling and forecasting of epidemic spreading: The case of Covid-19 and beyond. Chaos Solitons Fractals 2020, 135, 109794, doi:10.1016/j.chaos.2020.109794.

2. Tan, J.; Mu, L.; Huang, J.; Yu, S.; Chen, B.; Yin, J. An initial investigation of the association between the SARS outbreak and weather: with the view of the environmental temperature and its variation. J Epidemiol Community Health 2005, 59, 186-192, doi:10.1136/jech.2004.020180.

3. Runkle, J.D.; Sugg, M.M.; Leeper, R.D.; Rao, Y.; Matthews, J.L.; Rennie, J.J. Short-term effects of specific humidity and temperature on COVID-19 morbidity in select US cities. Sci Total Environ 2020, 740, 140093, doi:10.1016/j.scitotenv.2020.140093.

4. Shi, P.; Dong, Y.; Yan, H.; Li, X.; Zhao, C.; Liu, W.; He, M.; Tang, S.; Xi, S. The impact of temperature and absolute humidity on the coronavirus disease 2019 (COVID-19) outbreak - evidence from China. medRxiv 2020, 10.1101/2020.03.22.20038919, doi:10.1101/2020.03.22.20038919.

5. Aboubakr, H.A.; Sharafeldin, T.A.; Goyal, S.M. Stability of SARS-CoV-2 and other coronaviruses in the environment and on common touch surfaces and the influence of climatic conditions: a review. Transbound Emerg Dis 2020, 10.1111/tbed.13707, doi:10.1111/tbed.13707.

6. Chan, K.H.; Peiris, J.S.; Lam, S.Y.; Poon, L.L.; Yuen, K.Y.; Seto, W.H. The Effects of Temperature and Relative Humidity on the Viability of the SARS Coronavirus. Adv Virol 2011, 2011, 734690, doi:10.1155/2011/734690.

7. Sobral, M.F.F.; Duarte, G.B.; da Penha Sobral, A.I.G.; Marinho, M.L.M.; de Souza Melo, A. Association between climate variables and global transmission oF SARS-CoV-2. Sci Total Environ 2020, 729, 138997, doi:10.1016/j.scitotenv.2020.138997.

8. Liu, J.; Zhou, J.; Yao, J.; Zhang, X.; Li, L.; Xu, X.; He, X.; Wang, B.; Fu, S.; Niu, T., et al. Impact of meteorological factors on the COVID-19 transmission: A multi-city study in China. Sci Total Environ 2020, 726, 138513, doi:10.1016/j.scitotenv.2020.138513.

9. Ujiie, M.; Tsuzuki, S.; Ohmagari, N. Effect of temperature on the infectivity of COVID-19. Int J Infect Dis 2020, 95, 301-303, doi:10.1016/j.ijid.2020.04.068.

10. Auler, A.C.; Cassaro, F.A.M.; da Silva, V.O.; Pires, L.F. Evidence that high temperatures and intermediate relative humidity might favor the spread of COVID-19 in tropical climate: A case study for the most affected Brazilian 
$\begin{array}{llllll}\text { cities. } & \text { Sci } & \text { Total }\end{array}$ doi:10.1016/j.scitotenv.2020.139090.

11. Barreca, A.I.; Shimshack, J.P. Absolute humidity, temperature, and influenza mortality: 30 years of county-level evidence from the United States. Am J Epidemiol 2012, 176 Supp1 7, S114-122, doi:10.1093/aje/kws259.

12. Lin, K.; Yee-Tak Fong, D.; Zhu, B.; Karlberg, J. Environmental factors on the SARS epidemic: air temperature, passage of time and multiplicative effect of hospital infection. Epidemiol Infect 2006, 134, 223-230, doi:10.1017/s0950268805005054.

13. Wang, J.; McMichael, A.J.; Meng, B.; Becker, N.G.; Han, W.; Glass, K.; Wu, J.; Liu, X.; Liu, J.; Li, X., et al. Spatial dynamics of an epidemic of severe acute respiratory syndrome in an urban area. Bull World Health Organ 2006, 84, 965 968, doi:10.2471/blt.06.030247.

14. Cao, C.; Chen, W.; Zheng, S.; Zhao, J.; Wang, J.; Cao, W. Analysis of Spatiotemporal Characteristics of Pandemic SARS Spread in Mainland China. Biomed Res Int 2016, 2016, 7247983, doi:10.1155/2016/7247983.

15. Xie, J.; Zhu, Y. Association between ambient temperature and COVID-19 infection in 122 cities from China. Sci Total Environ 2020, 724, 138201, doi:10.1016/j.scitotenv.2020.138201.

16. Bashir, M.F.; Ma, B.; Bilal; Komal, B.; Bashir, M.A.; Tan, D.; Bashir, M. Correlation between climate indicators and COVID-19 pandemic in New York, USA. Sci Total Environ 2020, 728, 138835, doi:10.1016/j.scitotenv.2020.138835.

17. Wu, Y.; Jing, W.; Liu, J.; Ma, Q.; Yuan, J.; Wang, Y.; Du, M.; Liu, M. Effects of temperature and humidity on the daily new cases and new deaths of COVID-19 in 166 countries. Sci Total Environ 2020, 729, 139051, doi:10.1016/j.scitotenv.2020.139051.

18. Bhaskaran, K.; Gasparrini, A.; Hajat, S.; Smeeth, L.; Armstrong, B. Time series regression studies in environmental epidemiology. Int J Epidemiol 2013, 42, 1187-1195, doi:10.1093/ije/dyt092.

19. Gasparrini, A.; Armstrong, B.; Kenward, M.G. Distributed lag non-linear models. Stat Med 2010, 29, 2224-2234, doi:10.1002/sim.3940.

20. Yin, Q.; Wang, J. A better indicator to measure the effects of meteorological factors on cardiovascular mortality: heat index. Environ Sci Pollut Res Int 2018, 25, 22842-22849, doi:10.1007/s11356-018-2396-1.

21. Liu, K.; Hou, X.; Ren, Z.; Lowe, R.; Wang, Y.; Li, R.; Liu, X.; Sun, J.; Lu, L.; Song, $\mathrm{X}$., et al. Climate factors and the East Asian summer monsoon may drive large outbreaks of dengue in China. Environ Res 2020, 183, 109190, doi:10.1016/j.envres.2020.109190.

22. Ge, E.; Lai, K.; Xiao, X.; Luo, M.; Fang, Z.; Zeng, Y.; Ju, H.; Zhong, N. Differential effects of size-specific particulate matter on emergency department visits for respiratory and cardiovascular diseases in Guangzhou, China. Environ Pollut 2018, 243, 336-345, doi:10.1016/j.envpol.2018.08.068.

23. Cui, L.; Geng, X.; Ding, T.; Tang, J.; Xu, J.; Zhai, J. Impact of ambient 
temperature on hospital admissions for cardiovascular disease in Hefei City, China. Int J Biometeorol 2019, 63, 723-734, doi:10.1007/s00484-019-01687-0. 24. Chin, A.W.H.; Chu, J.T.S.; Perera, M.R.A.; Hui, K.P.Y.; Yen, H.-L.; Chan, M.C.W.; Peiris, M.; Poon, L.L.M. Stability of SARS-CoV-2 in different environmental conditions. The Lancet Microbe 2020, 1, doi:10.1016/s26665247(20)30003-3.

\section{Figure Title}

Fig. 1. The time series of the daily new confirmed cases(a), daily temperature(b), and relative humidity(c) 2020.1.27-2020.7.15.

Fig. 2. Three-dimension plot(a) and overall cumulative RR of daily new confirmed cases(b) with temperature.

Fig. 3. Three-dimension plot(a) and overall cumulative RR of daily new confirmed cases(b) with humidity.

Fig. 4. Single-day lagged effects of specific temperatures on COVID-19 at various lag days.

Fig. 5. Single-day lagged effects of specific humidity on COVID-19 at various lag days.

\section{Supplementary materials}

Fig. S1. Exposure-response diagram under different df $(2,4)$ between temperature and COVID-19.

Fig. S2. Exposure-response diagram under different df $(2,4)$ between humidity and COVID-19.

Fig. S3. Exposure-response diagram under between temperature, humidity, and COVID-19 when the maximum lag days $=6$.

Fig. S4. Exposure-response diagram under between temperature, humidity, and 
COVID-19 when the maximum lag days $=8$. 
Figures
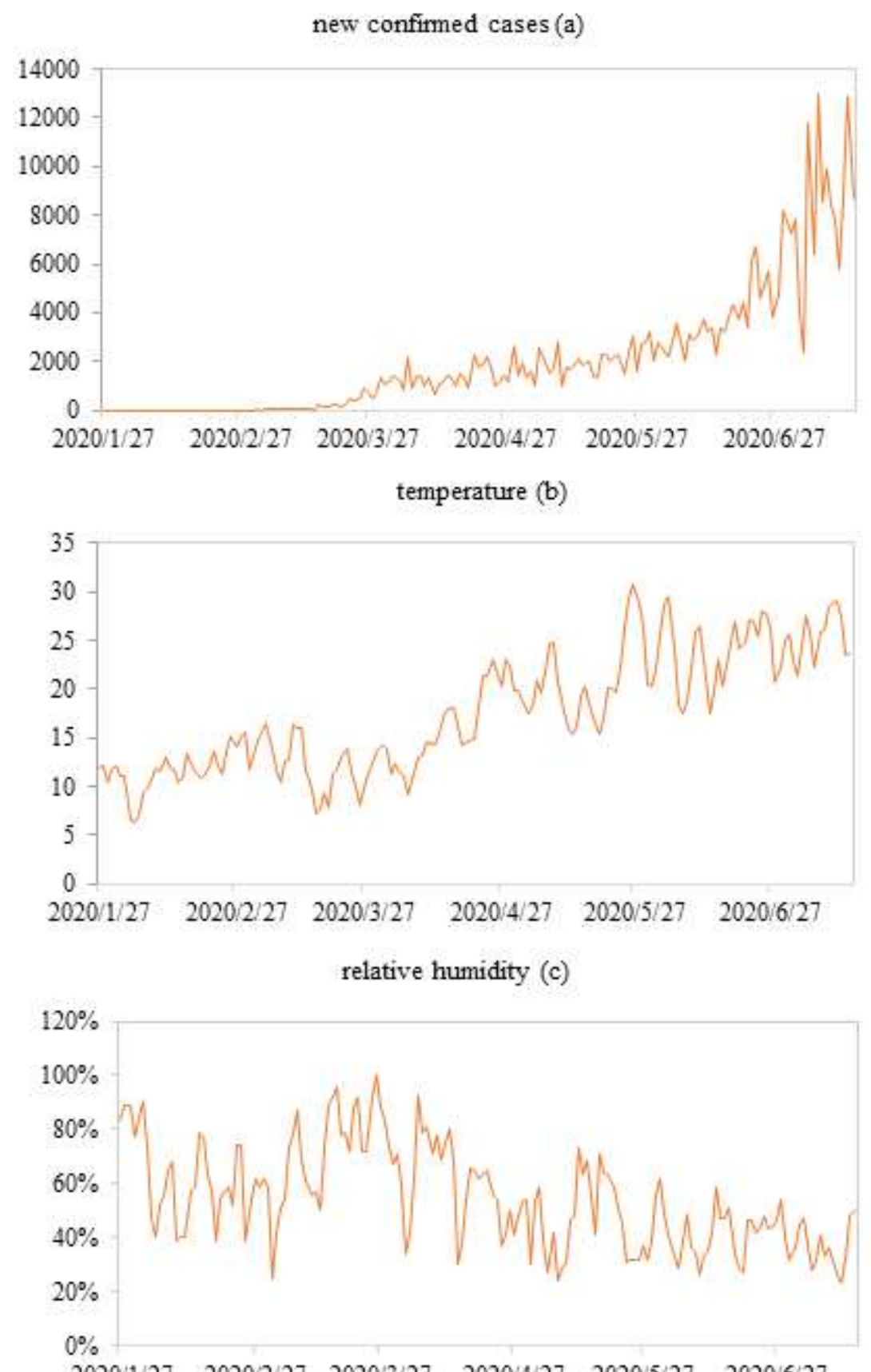

\section{Figure 1}

The time series of the daily new confirmed cases(a), daily temperature(b), and relative humidity(c) 2020.1.27-2020.7.15. 
temp 3D: default perspective

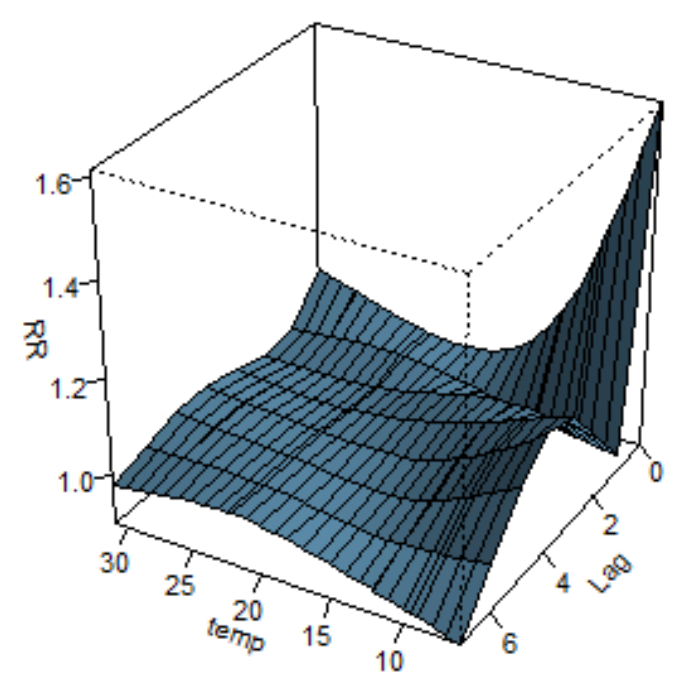

Overall cumulative association for 7 lags

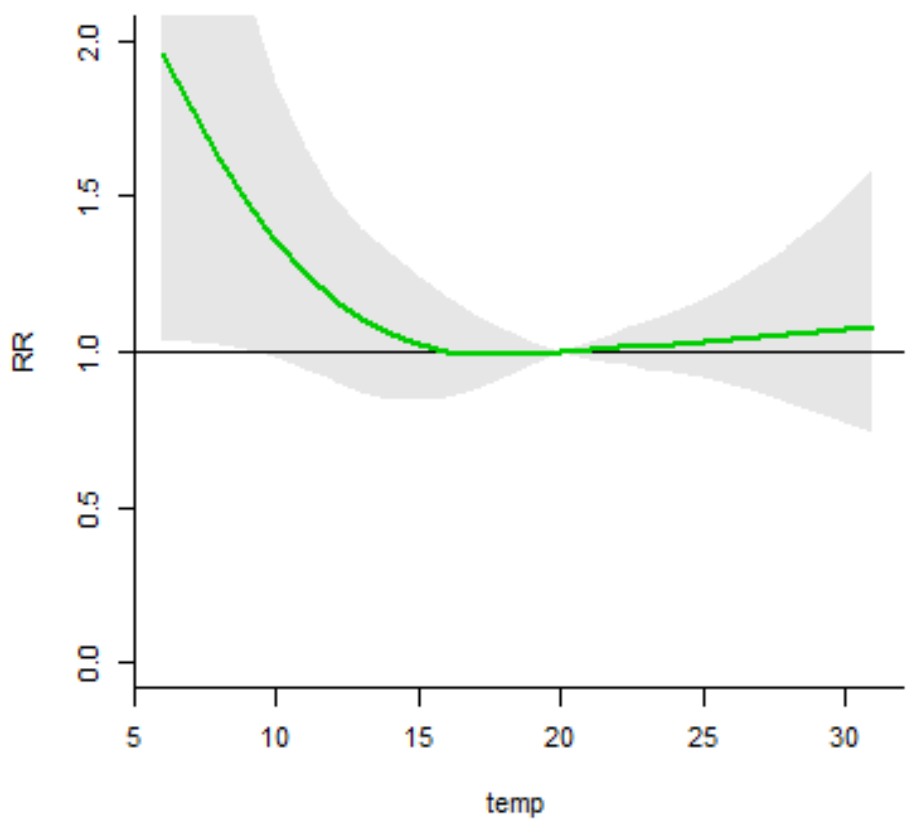

Figure 2

Three-dimension plot(a) and overall cumulative RR of daily new confirmed cases(b) with temperature.

RH 3D: default perspective

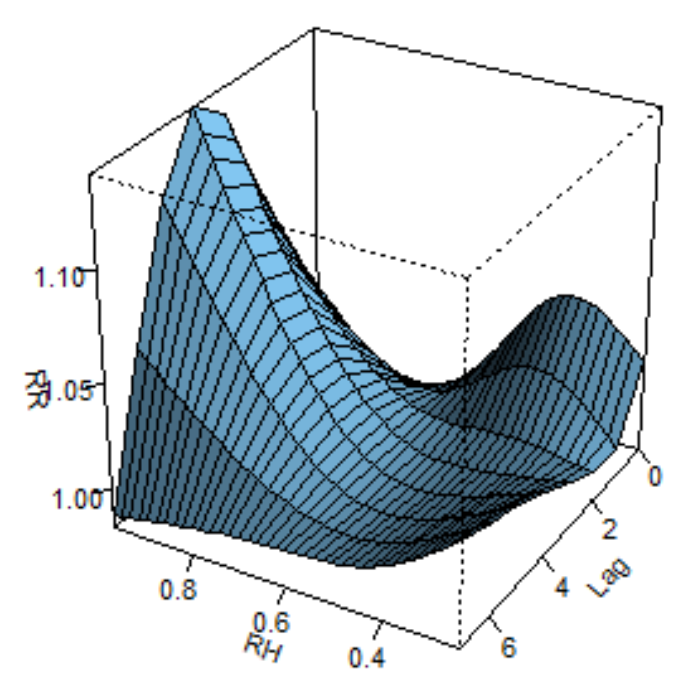

Overall cumulative association for 7 lags

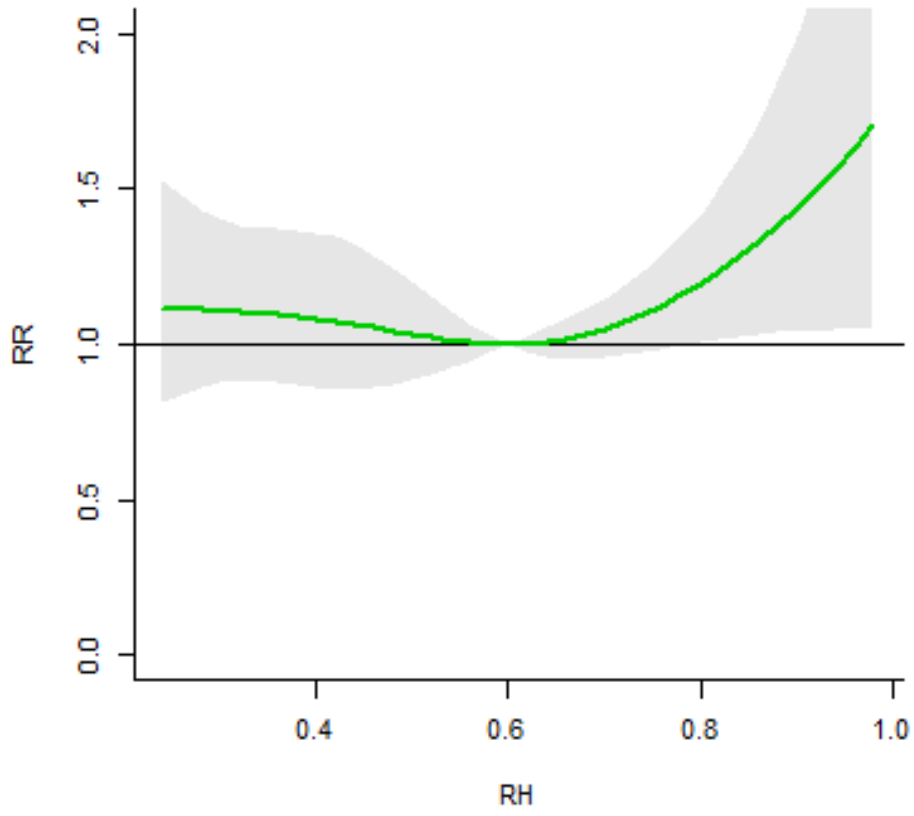

\section{Figure 3}

Three-dimension plot(a) and overall cumulative RR of daily new confirmed cases(b) with humidity. 


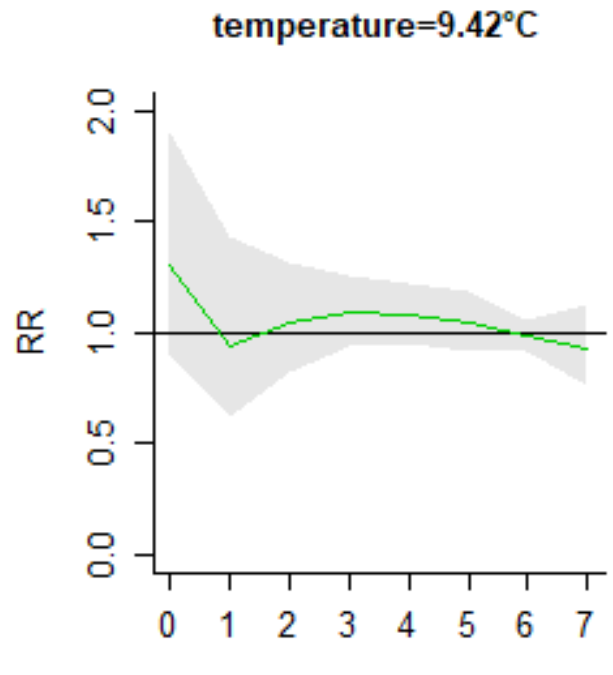

Lag

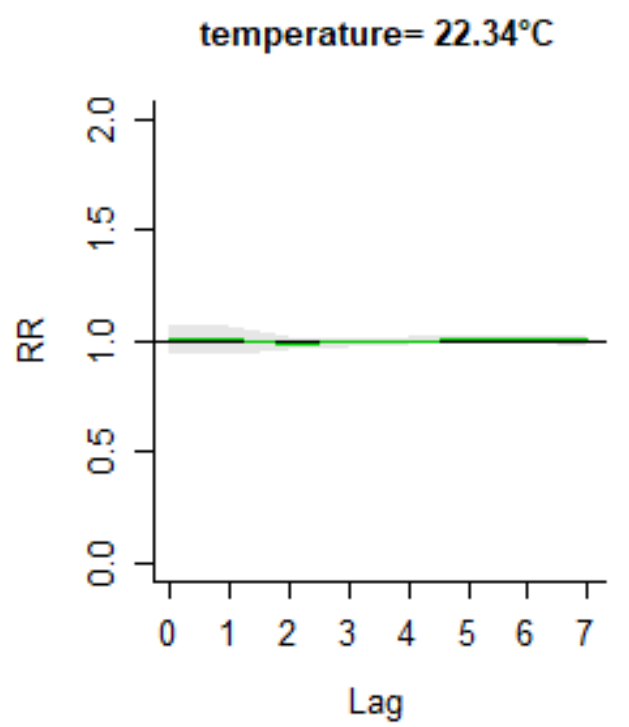

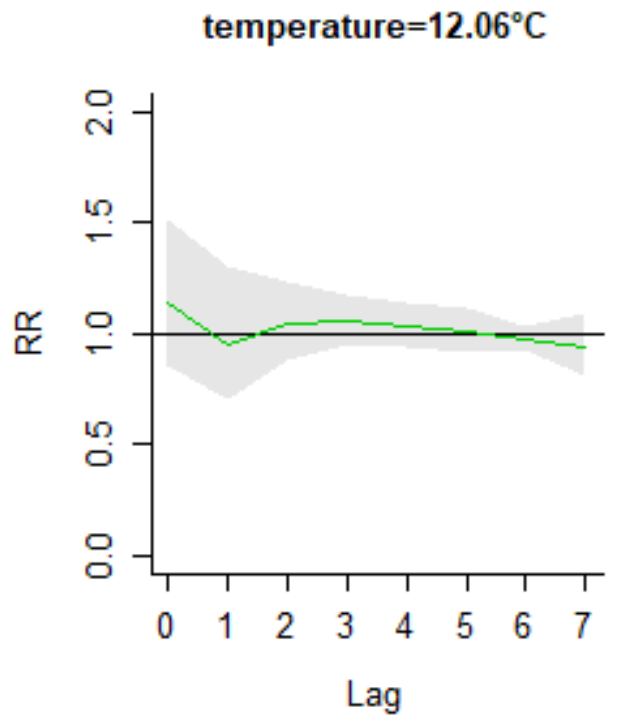

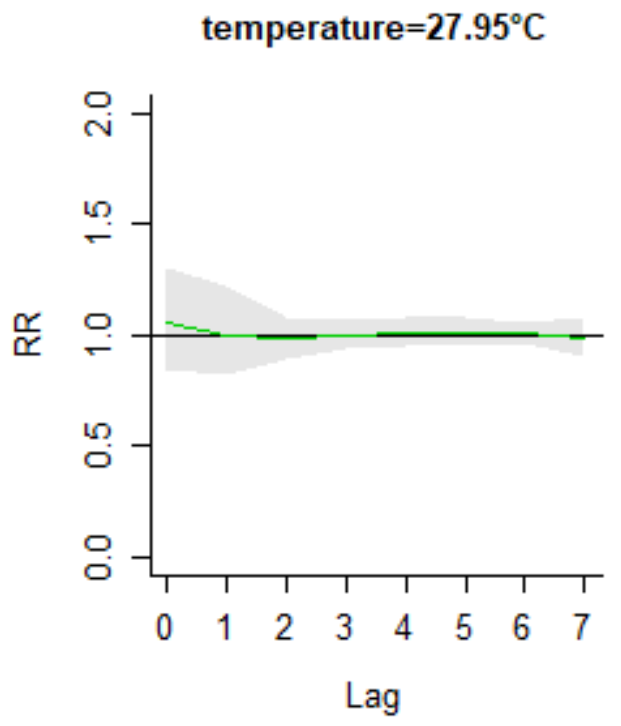

Figure 4

Single-day lagged effects of specific temperatures on COVID-19 at various lag days. 
$\mathrm{RH}=\mathbf{2 9 . 0} \%$

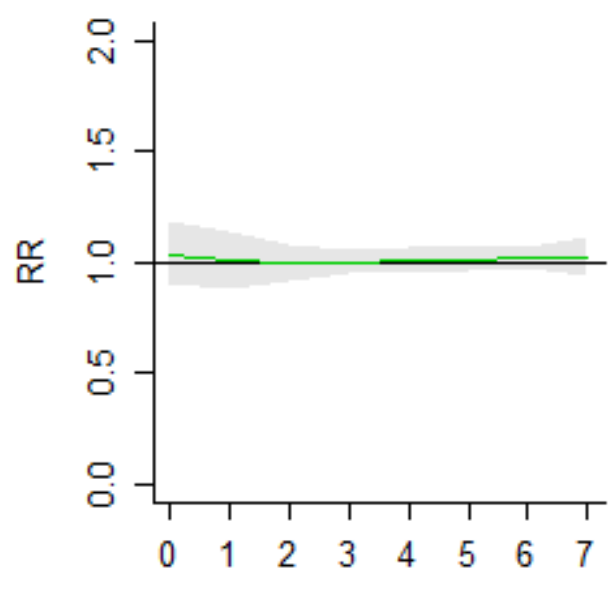

Lag

$\mathrm{RH}=69.0 \%$

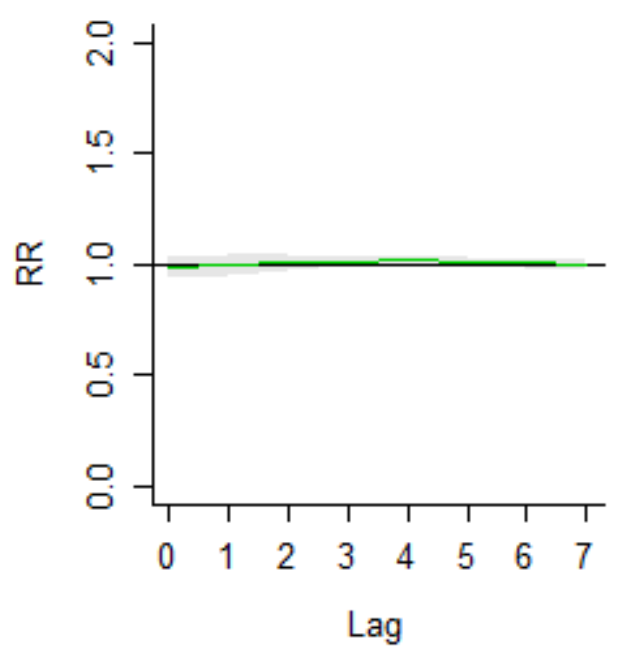

$\mathrm{RH}=39.5 \%$

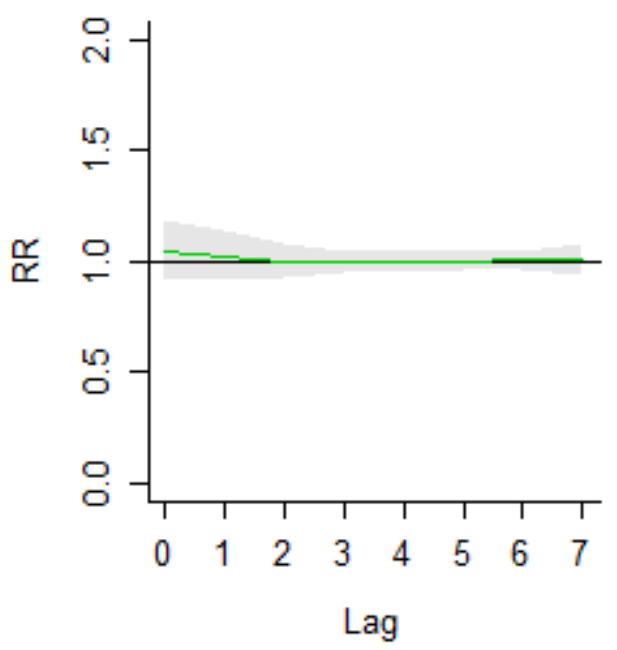

$\mathrm{RH}=89.0 \%$

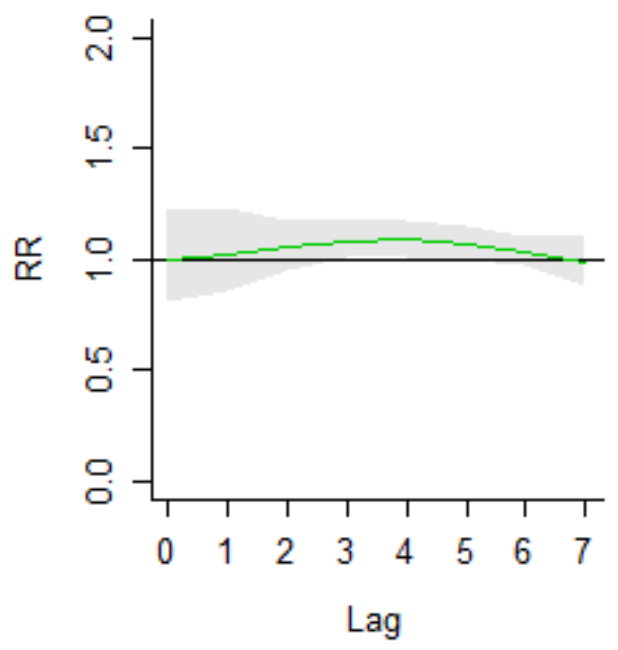

\section{Figure 5}

Single-day lagged effects of specific humidity on COVID-19 at various lag days.

\section{Supplementary Files}

This is a list of supplementary files associated with this preprint. Click to download.

- SupplementaryMaterial.docx 